\title{
Regulation of fruit and seed response to heat and drought by sugars as nutrients and signals
}

\author{
Yong-Hua Liu ${ }^{1,2}$, Christina E. Offler ${ }^{1}$ and Yong-Ling Ruan ${ }^{1 *}$ \\ 1 Department of Biology, School of Environmental and Life Sciences, The University of Newcastle, Newcastle, NSW, Australia \\ 2 Institute of Vegetables, Zhejiang Academy of Agricultural Sciences, Hangzhou, China
}

\author{
Edited by: \\ Sergey Shabala, University of \\ Tasmania, Australia \\ Reviewed by: \\ Gabriel Krouk, CNRS, France \\ Matthew Paul, Rothamsted \\ Research, UK \\ *Correspondence: \\ Yong-Ling Ruan, Department of \\ Biology, School of Environmental \\ and Life Sciences, The University of \\ Newcastle, Newcastle, NSW, \\ Australia \\ e-mail: yong-ling.ruan@ \\ newcastle.edu.au
}

A large body of evidence shows that sugars function both as nutrients and signals to regulate fruit and seed set under normal and stress conditions including heat and drought. Inadequate sucrose import to, and its degradation within, reproductive organs cause fruit and seed abortion under heat and drought. As nutrients, sucrose-derived hexoses provide carbon skeletons and energy for growth and development of fruits and seeds. Sugar metabolism can also alleviate the impact of stress on fruit and seed through facilitating biosynthesis of heat shock proteins (Hsps) and non-enzymic antioxidants (e.g., glutathione, ascorbic acid), which collectively maintain the integrity of membranes and prevent programmed cell death (PCD) through protecting proteins and scavenging reactive oxygen species (ROS). In parallel, sugars (sucrose, glucose, and fructose), also exert signaling roles through cross-talk with hormone and ROS signaling pathways and by mediating cell division and PCD. At the same time, emerging data indicate that sugar-derived signaling systems, including trehalose-6 phosphate (T6P), sucrose non-fermenting related kinase-1 (SnRK), and the target of rapamycin (TOR) kinase complex also play important roles in regulating plant development through modulating nutrient and energy signaling and metabolic processes, especially under abiotic stresses where sugar availability is low. This review aims to evaluate recent progress of research on abiotic stress responses of reproductive organs focusing on roles of sugar metabolism and signaling and addressing the possible biochemical and molecular mechanism by which sugars regulate fruit and seed set under heat and drought.

Keywords: sugar metabolism and signaling, fruit and seed set, heat and drought, cell division, hormones, programmed cell death, reactive oxygen species, non-enzymic antioxidant

\section{INTRODUCTION}

Food security is becoming a more and more important and urgent issue with increasing demand for enhancement of crop yield. It is estimated that more than 1 billion people are currently undernourished worldwide (Garrity et al., 2010; Godfray et al., 2010) and the world population is predicted to reach more than 9 billion by 2050 (Fedoroff et al., 2010). To meet this population growth crop yield must be doubled by the middle of this century (Beddington, 2010). Unfortunately, the arable land area for food production is rapidly decreasing because of urbanization, salinization, desertification, and competition from biofuel production (Döös, 2002; Solomon, 2010). This means we have to significantly increase crop yield per unit land area to meet the increasing food demand.

Increasing crop yield is becoming more challenging with global warming. It has been predicted that there will be $1.5-5.8^{\circ} \mathrm{C}$ increase in average annual temperatures by 2100 (Zinn et al., 2010) and approximately $2.5-16 \%$ yield loss for every $1{ }^{\circ} \mathrm{C}$ increase in temperature above optima (Battisti and Naylor, 2009). Furthermore, in field conditions, drought often occurs simultaneously with heat and the combination of drought and heat can lead to a synergistic detrimental effect on crop productivity (Rampino et al., 2012).
The development of reproductive organs (mainly fruits and seeds and their precursors, ovaries and ovules) plays a dominant role in global crop production. In the top fifteen major crops worldwide, there are 10 crops that are consumed as fruit and seed crops (Ross-Ibarra et al., 2007). Generally, about $75 \%$ of the total worldwide crop yield comes from fruit and seed crops (Ruan et al., 2010). Fruit and seed yield is mainly determined by fruit and seed number and their size. Fruit and seed abortion is a major limiting factor for achieving crop yield potential (Boyer and McLaughlin, 2007; Patrick and Stoddard, 2010; Ruan et al., 2012). In the plant life cycle, the early stage of fruit and seed development at the set phase is one of the most sensitive periods to abiotic stresses such as heat, drought, and cold (Barnabás et al., 2008; Hedhly et al., 2008; Thakur et al., 2010). Abiotic stresses during the early reproductive stage often cause abnormal development of reproductive organs that results in failure of fertilization or abortion of fruits and seeds (Thakur et al., 2010), thereby dramatically decreasing crop yield (Setter et al., 2011; Kakumanu et al., 2012). For example, drought at the flowering stage caused severe kernel abortion in maize (McLaughlin and Boyer, 2004a). In tomato, flower abortion rate can reach up to $80 \%$ under heat stress (Ruan et al., 2010). Similarly, seed set of Brassica napus was reduced by $88 \%$ by heat stress (Young et al., 2004). Thus, increasing fruit 
and seed set under various abiotic stresses is a viable option for sustaining crop yield in the face of climate change. Despite the importance and sensitivity of the fruit and seed set processes, most research effort in fruit and seed biology to date has been dedicated to the late stage of growth and maturation of fruit and seed (Wang et al., 2009), and little is known about the physiological and molecular mechanisms regulating fruit and seed set under abiotic stresses (Ruan et al., 2012).

\section{SUGAR METABOLISM IN FRUIT AND SEED DEVELOPMENT}

Fruit and seed development depends on import of sugars in the form of sucrose transported through phloem from source leaves in most species (Egli, 2010; Foulkes et al., 2011) since fruit photosynthesis is negligible in terms of its contribution of assimilates to fruit development (Blanke and Lenz, 1989). This conclusion is supported by a recent molecular study where the specific suppression of glutamate 1-semialdehyde aminotransferase (GSA) in fruits, a key enzyme in chlorophyll biosynthesis, had no effect on fruit growth and ripening (Lytovchenko et al., 2011). However, fruit photosynthesis plays vital roles in early seed development since seed set was seriously compromised in the transgenic plants, indicating early seed development is more sensitive to reduction of carbon supply than fruit. Before participating in various physiological and metabolic processes, phloem-unloaded sucrose must be degraded into hexoses (glucose and fructose) or their derivates by sucrose synthase (Sus, EC 2.4.1.13) or invertase (INV, EC 3.2.1.26) (Sturm, 1999). Sus is a glycosyl transferase, which reversibly converts sucrose in the presence of UDP into UDPglucose and fructose, whereas INV irreversibly hydrolyses sucrose into glucose and fructose. Based on their subcellular location, INVs can be classified into three subgroups: cell wall invertase (CWIN), vacuolar invertase (VIN), and cytoplasmic invertase (CIN) (Sturm, 1999).

Sugar metabolism provides not only energy to power numerous cellular processes, but also substrates for biosynthesis of biopolymers such as starch, cellulose, callose, and protein. At the same time, sucrose metabolism in sink organs can help to establish sink strength by lowering sucrose concentration in recipient sink cells thereby facilitating sucrose import from source to sink (Ho, 1988). Furthermore, hexose produced by INV and Susmediated sucrose degradation can act as a signaling molecule to regulate plant development (Ruan, 2012). It has been suggested that INV and Sus may play particularly important roles in bulky organs such as fruits and seeds in many crop species as compared to that in their wild progenitors (Xu et al., 2012). For example, the loss of a functional CWIN in maize kernels resulted in a miniature seed phenotype (Miller and Chourey, 1992). Similarly, specific overexpression of CWIN in rice by its native promoter increased grain yield (Wang et al., 2008). In contrast, silencing CWIN expression in tomato resulted in increased fruit abortion, and reduced fruit size and seed number per plant (Zanor et al., 2009).

\section{CENTRAL ROLES OF SUGAR METABOLISM IN FRUIT AND SEED SET UNDER HEAT AND DROUGHT}

Compared to vegetative organs, young reproductive organs are less competitive for nutrient acquisition, which may result from their distal location from source leaves, lower transport conductivities through plasmodesmata and differentiating phloem and their low INV activities (Ruan et al., 2012). Thus, even under optimal conditions, sugar availability could become one limiting factor for fruit and seed set (Ghiglione et al., 2008).

Under heat and drought, sugar limitation is a well-known factor leading to fruit and seed abortion (Boyer and McLaughlin, 2007; Barnabás et al., 2008). For example, as a result of heat stress, the growth rate of pollen tubes through the style of cotton is limited by an inadequate supply of sucrose and hexose in the pistil (Snider et al., 2011). In maize, drought resulted in severe ovary abortion, while feeding sucrose to the stems of water-stressed plants partially prevented the abortion and restored kernel number (Zinselmeier et al., 1999; McLaughlin and Boyer, 2004a) demonstrating that low availability of sucrose or hexose is a casual factor of ovary abortion. Further analyses revealed that ovary abortion was linked more closely to the availability of glucose than sucrose in the ovary (McLaughlin and Boyer, 2004a), since sucrose concentrations were completely restored after sucrose feeding but glucose concentrations were only partially restored (Zinselmeier et al., 1999). Therefore, inefficient conversion of sucrose to glucose and fructose is a key limiting step for ovary development under drought. In fact, McLaughlin and Boyer (2004b) showed that sucrose feeding only partially restored the activity of invertase which was decreased under drought. Consistently, silencing of CWIN gene (Lin5) in tomato increased fruit abortion under drought (Zanor et al., 2009). On the other hand, elevation in CWIN activity through silencing expression of the CWIN inhibitor in tomato delayed leaf senescence and enhanced fruit and seed development (Jin et al., 2009). It will be important to determine if these CWIN-elevated transgenic plants exhibit increased tolerance to abiotic stress.

\section{POSSIBLE MECHANISMS UNDERLYING REGULATION OF FRUIT AND SEED SET BY SUGARS AS NUTRIENTS UNDER HEAT AND DROUGHT}

Sucrose metabolism not only provides energy and carbon skeletons for sink development, but also regulates their response to abiotic stresses by providing hexoses as essential metabolites and signaling molecules (Ruan et al., 2012).

\section{REGULATION OF CARBON PARTITIONING}

Mild heat stress before silking enhanced the total biomass of maize plants, but with reduced grain yield (Suwa et al., 2010) which indicates that carbon partitioning favors vegetative organs over reproductive tissues when under stress. The difference in response to abiotic stresses between reproductive and vegetative organs may be related to different responses of sucrose degrading enzymes to stress conditions. For example, drought induced the expression of VIN ( Ivr 2 ) in vegetative tissues of maize, but reduced the expression of $I v r 2$ in reproductive organs (Kim et al., 2000). Similar result was also observed in soybean in which drought decreased the activity of soluble invertase in pods, but not that in leaves (Liu et al., 2004). By using RNA-Seq analysis, Kakumanu et al. (2012) found that there are more genes related to carbohydrate metabolism responsive to drought in the maize 
ovary than in young leaves. Among them, one gene encoding sucrose synthase showed decreased expression in the ovary, but not in leaf meristems, under drought. This may decrease the sink strength of these reproductive organs leading to sucrose partitioning in favor of vegetative tissues (Sturm and Tang, 1999; Andersen et al., 2002). Consistent with this postulation, a heat tolerant tomato genotype exhibited higher CWIN and VIN activities in the flower and young fruit and consequently a higher rate of sucrose import into young fruit than a heat sensitive genotype, which collectively contributed to higher fruit set under heat stress (Li et al., 2012). Thus, a high ability of sucrose partitioning to, and its degradation within, reproductive organs could be vital for fruit and seed set under heat and drought.

\section{SUCROSE METABOLISM CONTRIBUTES TO ANTIOXIDANT PROTECTION}

Heat and drought often lead to excess accumulation of reactive oxygen species (ROS), including singlet oxygen, superoxide $\left(\mathrm{O}_{2}^{-}\right)$, hydrogen peroxide $\left(\mathrm{H}_{2} \mathrm{O}_{2}\right)$, and the hydroxyl radical $\left(\mathrm{OH}^{-}\right)$, which may result in oxidative damage of DNA, proteins, and lipids (Oktyabrsky and Smirnova, 2007), and finally programmed cell death (PCD) and fruit and seed abortion (Laloi et al., 2004; Vacca et al., 2004; Foyer and Noctor, 2005). It has been proposed that sugar limitation caused by various stresses might be an important basis for ROS accumulation (Couée et al., 2006; Bolouri-Moghaddam et al., 2010). Glucose metabolism may play positive roles in preventing PCD by scavenging ROS. As the primary carbon and energy source in plants, glucose can feed the oxidative pentose phosphate pathway and produce reducing power for biosynthesis of non-enzymic antioxidants such as glutathione (GSH), ascorbic acid (Asc), phenolic compounds, and flavonoids (Bolouri-Moghaddam et al., 2010), which can efficiently scavenge ROS. Glucose-6-phosphate dehydrogenase $(\mathrm{G} 6 \mathrm{PDH})$ is the rate-limiting enzyme in the oxidative pentose phosphate pathway. A study on soybean showed that G6PDH plays a central role in maintaining the ROS homeostasis under drought stress through increasing the activities of glutathione reductase (GR), dehydroascorbate reductase (DHAR), and monodehydroascorbate reductase (MDHAR) and the content of GSH and Asc (Liu et al., 2013). In addition, oxidative stresses caused by high light and herbicide, paraquat, can activate antioxidant response in Arabidopsis plants (Sunkar et al., 2006). However, exogenous addition of sucrose to Arabidopsis reduced the expression of SOD genes (CSD1 and CSD2) under high light and paraquat, implying sucrose might prevent oxidant stress to some extent (Dugas and Bartel, 2008). Furthermore, some soluble sugars, such as fructan, might act as ROS scavengers themselves when they exist at high concentration (Van den Ende and Valluru, 2009). Further evidence on sucrose metabolism alleviating oxidative stress comes from transgenic potato plants overexpressing yeast INV that displayed lower malondialdehyde (MDA) content under cold stress (Sinkevich et al., 2010). This indicates INV may improve cold tolerance through enhancing the antioxidant capability of potato plants (Sinkevich et al., 2010). Another example is that oxidative stress such as that caused by application of $\mathrm{H}_{2} \mathrm{O}_{2}$ often increases the expression of ascorbate peroxidases (APXs), enzymes playing important roles in maintaining the plant's antioxidant system. Overexpressing CIN in Arabidopsis protoplasts, however, alleviates the elevation of APX expression upon $\mathrm{H}_{2} \mathrm{O}_{2}$ application, which implies that CIN may ameliorate oxidative stress directly (Xiang et al., 2011). Although the majority of these studies were conducted in vegetative tissues, it can be envisaged that sugar metabolism may play positive roles in fruit and seed set through maintaining ROS homeostasis under heat and drought.

\section{SUCROSE METABOLISM AND HEAT SHOCK PROTEINS (Hsps)}

Sugar metabolism may also ameliorate effects of abiotic stresses by fueling biosynthesis of heat shock proteins (Hsps). Under heat and drought, Hsps are often induced to prevent or attenuate stress-induced PCD though preserving membrane integrity and protein function. Severe heat stress could lead to the hyperfluidization and disruption of membranes (Horváth et al., 1998; Sangwan et al., 2002), inactivation of proteins by unfolding, misfolding, and aggregation (Sharma et al., 2010) and the accumulation of ROS (Dat et al., 1998; Volkov et al., 2006). These detrimental effects collectively damage photosynthesis and retard plant growth and development and may even cause death of sensitive tissues (Mittler and Blumwald, 2010). During evolution, plants have developed a system of heat-inducible cellular and molecular defences, i.e., the heat stress response (HSR). During HSR, hundreds of specific genes become up-regulated (Mittler et al., 2012). Among them, accumulation of Hsps is a major feature of HSR. Many of the Hsps are chaperones, including Hsp100s, Hsp90s, Hsp70s, Hsp60s, and small Hsps (sHsps) (Finka et al., 2011). Chaperones can prevent protein aggregation or restore misfolded and aggregated proteins to correctly-folded polypeptides. These polypetides can recover their active conformation for normal function after stress exposure (Sharma et al., 2010). Thus, Hsps play an important role in plant heat tolerance. Indeed, constitutive overexpression of Hsp17.7 in carrot (Malik et al., 1999) or Hsp101 in Arabidopsis (Queitsch et al., 2000) increased their heat tolerance.

Studies in animal systems showed that Hsp chaperones (e.g., Hsp70 and sHsps) can block PCD (Beere, 2004; Weiss et al., 2007). In Arabidopsis, CNGC2 encodes a component of cyclic nucleotide gated $\mathrm{Ca}^{2+}$ channels which are a kind of thermosensor in land plants. CNGC2 mutants accumulated Hsps at lower heat-priming temperatures and consequently have higher heat tolerance and less PCD than wild-type plants (Finka et al., 2012). Surprisingly, CNGC2 mutants showed growth retardation under control temperature, but without other detectable cellular, morphological, or developmental defects. It has been suggested that this may result from insufficient supply of photoassimilates since maintaining of HSR comes at a high energetic and metabolic cost (Finka et al., 2012; Mittler et al., 2012). Support for this hypothesis comes from a recent finding that heat-stress induced expression of two HSP genes, LeHSP17.4-CII and LeHSP17.6-CII, correlates with enhanced transcript levels and activities of VIN in 5-d tomato fruit (Li et al., 2012). However, evidence is still lacking as to whether, and to what extent, induction of Hsps is dependent on glucose metabolism and signaling that is coupled with INV activity. 


\section{POSSIBLE MECHANISMS UNDERLYING REGULATION OF FRUIT AND SEED SET BY SUGARS AS SIGNALS UNDER HEAT AND DROUGHT}

Sucrose metabolism also plays signaling roles in many developmental processes (Ruan, 2012), where sucrose and its degrading products, glucose and fructose, can act as signaling molecules to regulate gene expression (Moore et al., 2003; Wind et al., 2010; Cho and Yoo, 2011). However, it is difficult to distinguish the specific signaling role of sucrose from hexoses since sucrose can be quickly degraded into glucose and fructose. Thus, although the role of sucrose as a signaling molecule in plants was proposed several decades ago, it has been experimentally established and accepted only recently based on emerging evidence (Tognetti et al., 2013). For example, application of exogenous sucrose to the aerial part of Arabidopsis plants facilitate the initiation of lateral roots, but equal molar concentrations of glucose or fructose promote lateral root formation to a much lesser extent (Macgregor et al., 2008). Most recent studies on strawberry (Fragaria $\times$ ananassa) show that sucrose is the key signaling molecule in fruit ripening (Jia et al., 2013). Exogenous sucrose increased ABA content in fruit and accelerated fruit ripening which can be mimicked by turanose, a sucrose non-metabolizable analog, implying the possible signaling role of sucrose in fruit ripening. Their further studies revealed that silencing of the sucrose transporter (FaSUT1) by RNAi technique decreased sucrose level and blocked fruit ripening, whereas overexpression of FaSUT1 increased sucrose level and accelerated fruit ripening (Jia et al., 2013). However, no sucrose-specific sensor has been identified thus far (Wind et al., 2010), and little is known about the nature of sucrose signaling and the regulatory pathways modulated by sucrose.

Recently, it has been suggested that hexoses derived from sucrose cleavage by Sus and INV play important roles in plant development through signaling pathways (Koch, 2004; Ruan, 2012). However, up to now, research on sugar signaling has mainly focused on glucose (Smeekens et al., 2010; Cho and Yoo, 2011). Although fructose is also an abundant hexose produced from both INV- and Sus-catalysed sucrose degradation, little is known about its potential signaling role. Only recently, a systematic study was done in Arabidopsis which revealed that fructose signaling plays an important role in seedling development and fructose-1, 6-biphosphatase was identified as the fructose sensor in the signaling pathway (Cho and Yoo, 2011).

In addition to the above mentioned sugar signaling (i.e., sucrose, glucose, and fructose), the importance of some sugarderived signaling systems in plant development is becoming increasingly prominent. These systems include the trehalose 6phosphate (T6P) signal, and the target of rapamycin (TOR) kinase system, the SNF1-related protein kinase (SnRK) and bZIP transcription factor network. Here, we will first focus on the recent progress about the regulatory role of sugar (mainly glucose) signaling in fruit and seed development under abiotic stresses followed by discussion of the possible roles of T6P, TOR, SnRK1, and bZIP in plant development under abiotic stress.

\section{CROSSTALK BETWEEN SUGAR- AND HORMONE-SIGNALING PATHWAYS: A GENERAL PHENOMENON}

There is compelling evidence on crosstalk between sugar- and hormone-signaling pathways (LeClere et al., 2010; Ruan, 2012). For example, increased petal and sepal number in tomato in response to inhibition of CWIN gene (Lin5) expression is linked to decreased ABA, JA and GA levels (Zanor et al., 2009). Most studies focus on the positive interaction between sugars and auxins, an important hormone in plant development. The Arabidopsis hexokinase (HXK) mutant gin2 (glucose insensitive 2) is less sensitive to exogenous auxin indicating that the glucosesignaling pathway interacts with, or may act downstream of, the auxin signaling pathways through the HXK-dependent pathway (Moore et al., 2003). On the other hand, a recent study on Arabidopsis provides direct evidence that auxin biosynthesis is tightly dependent on endogenous glucose level (Sairanen et al., 2012). Consistently, exogenous glucose up-regulated the expressions of auxin biosynthetic genes (YUCCA) and IAA transporter genes (PINs) in roots of young Arabidopsis seedlings, and an auxin receptor mutant (tirl) and response mutants (axr2, axr3 and $\operatorname{sir} 1$ ) showed a defect in glucose-induced root elongation and lateral root production (Mishra et al., 2009). Decrease of hexose level in basal regions of maize kernels by deficiency of CWIN activity results in reduced IAA levels in miniature kernels that are related to suppressed expression of the IAA biosynthesis gene $(Z m Y U C)$ through a HXK-dependent pathway (LeClere et al., 2010). There is also a positive relationship between sugar and cytokinin signaling. For example, delayed leaf senescence by cytokinin depends on expression of CWIN in tobacco leaves (Lara et al., 2004), which implies a positive relationship between sugar and cytokinin signaling.

A negative interaction exists between glucose and ethylene through ETHYLENE-INSENSITIVE3 (EIN3), a key transcriptional regulator in ethylene signaling (Chao et al., 1997). Glucose can suppress the activity of EINs by enhancing their degradation through ubiquitination. Importantly, the non-signaling glucose analog, 3-O-methyl-glucose (3-OMG) which can not be phosphorylated by HXK in plants, did not suppress the activity of EIN3. This finding indicates that glucose acted as a signal molecule to induce the degradation of EIN3 in a HXK dependent manner (Yanagisawa et al., 2003). Indirect evidence also showed a negative interaction between sugars (hexoses) and ABA. For example, increased CWIN activity by silencing expression of CWIN inhibitor (LeINVINH1) delayed ABA-induced leaf senescence in tomato, which suggests ABA-mediated senescence is dependent on decreased CWIN activity, hence possibly a lower glucose or fructose level in the apoplasm (Jin et al., 2009). Interestingly, a study on rice anthers showed that ABA accumulation, prior to decreased CWIN and monosaccharide transporter expression, is the initial event responsible for pollen sterility under cold treatment (Oliver et al., 2007). Similarly, an increase in ABA level in maize ovaries occurred immediately after drought was imposed which is followed by a decrease in expression of soluble invertase (Ivr2) (Andersen et al., 2002). However, Pinheiro et al. (2011) found that a change in carbohydrate metabolism rather than in ABA level is the initial response of Lupinus albus to slowly imposed drought. This contradictory 
conclusion may be resulted from variability in type and strength of stress imposed.

Reciprocally, hormones can also affect sugar metabolism. For example, exogenous supplement of NAA to tobacco cells stimulated the activity of CWIN (Weil and Rausch, 1990). The induction of CWIN by cytokinins was observed in suspension cell cultures of Chenopodium rubrum (Ehness and Roitsch, 1997), and the result is further supported by the induction of CWIN activity by an endogenous increase of cytokinin in tobacco (Lara et al., 2004). Exogenous ABA decreased the CWIN activity in tomato leaves mainly through increasing the expression of CWIN inhibitor (INVINH1) (Jin et al., 2009). Overall, there appears to be synergistic relationships between CWIN activity and growth-related hormones (auxin, cytokinin), but antagonistic relationships between CWIN and senescence hormones (ABA and ethylene).

\section{SUGAR SIGNALING AND CELL DIVISION IN FRUITS AND SEEDS UNDER HEAT AND DROUGHT STRESS}

Early evidence about sugar signaling in reproductive organs comes from the observation that hexoses stimulate cell division, while sucrose promotes cell endoreduplication and starch accumulation in Vicia faba cotyledons (Weber et al., 1996). These authors further proposed that CWIN in the seed coat of Vicia faba can affect the developmental processes of seeds through regulating sugar signaling in the embryo. In maize, mutation of a CWIN gene (INCW2) resulted in a miniature seed phenotype by blocking endosperm cell division (Vilhar et al., 2002). Further, Baldet et al. (2006) suggested that the possible mechanism for carbohydrate control of tomato fruit size is through the regulation of cell proliferation. The effect of sugar signaling on cell division in seed and fruit may be realized through their regulation of cyclins (e.g., cyclin D-Dewitte and Murray, 2003; Weber et al., 2005). It has been suggested that decreased glucose level under stress conditions could repress cell division and consequently lead to fruit and seed abortion (Ruan et al., 2012). A recent study showed that drought inhibited the expression of two main invertase genes, Incw 1 and Incw 2, in the maize ovary and decreased the hexose level (Kakumanu et al., 2012). It has been suggested that this reduced hexose level arrested cell division through decreasing the expression of cyclins and increasing the expression of the cyclin-dependent kinase inhibitor (CDKI). Consistently, in the more resistant leaf meristem, drought increased invertase expression, which maintained the hexose level and cell division activity.

Sugar signaling regulation of cell division might be realized through crosstalk with hormone signaling. It has been proposed that normal fruit and seed development relies on induction of auxin, GA and cytokinin responses and attenuation of ethylene and ABA responses (Dorcey et al., 2009; Ji et al., 2011; Ruan et al., 2012). Auxin, GA and cytokinin can facilitate fruit and seed set and development by enhancing cell division and cell expansion (Gillaspy et al., 1993), whereas ethylene and ABA are senescence and stress hormones which can hamper fruit and seed development (Davies, 2010). It can be postulated that, therefore, under optimal conditions, glucose signals can promote cell division, and consequently fruit and seed set through enhancing growth-related hormone signaling (auxin, GA and cytokinin, Figure 1A). Under stress conditions, however, decreased glucose levels resulting from reduced sucrose import into, and INV activity within, ovaries and seeds may lead to activation of senescence hormone signaling (ethylene and $\mathrm{ABA}$ ) and arrest cell division, and finally fruit and seed abortion (Figure 1B).

\section{CROSSTALK BETWEEN SUGAR-AND ROS-SIGNALING PATHWAYS}

As detailed above, excess ROS will damage DNA, proteins and lipids. However, ROS also play a signaling role at lower concentrations, which is essential for many developmental or metabolic processes such as PCD, cell wall biosynthesis, and stress responses (Kovtun et al., 2000; Mittler, 2002; Andriunas et al., 2012). An important mechanism of ROS signaling is to regulate the interaction between proteins through altering the redox state of amino acids such as cysteine (Cys). ROS can also play their signaling role through calcium signaling and affecting transcription factors (Munné-Bosch et al., 2013). Among all the ROS species, $\mathrm{H}_{2} \mathrm{O}_{2}$ is the most common signaling molecule since it is relatively stable and water-soluble (Bienert et al., 2007; Van Breusegem et al., 2008). Under stress conditions, maintaining ROS at an optimal level can facilitate their beneficial signaling function without causing oxidative damage (Liu et al., 2013). As discussed earlier, sugar metabolism plays important roles in maintaining ROS homeostasis. It has also been proposed that there is an interaction between sugar- and ROS-signaling pathways (Bolouri-Moghaddam et al., 2010). Thus, it can be inferred that sugar metabolism may play its signaling role indirectly through interacting with ROS signaling, particularly under stress conditions.

\section{ROLES OF OTHER SUGAR-DERIVED SIGNALING SYSTEMS IN THE ABIOTIC STRESS RESPONSE TREHALOSE AND TREHALOSE-6-PHOSPHATE}

Trehalose is a non-reducing disaccharide sugar, which is synthesized by trehalose-6-phosphate synthase (TPS) and trehalose6-phosphate phosphatase (TPP). TPS catalyzes the formation of trehalose-6-phosphate (T6P) from glucose-6-phosphate and UDP-glucose, while TPP is responsible for the dephosphorylation of T6P to produce trehalose (Eastmond et al., 2002). Trehalose is ubiquitous in the biosphere, but only in trace amounts in most plants. Although plenty of evidence indicates that trehalose may play important regulatory roles in plant development and resistance to diverse abiotic stresses (Li et al., 2011), emerging evidence has proposed that T6P, rather than trehalose, is the main active component in trehalose metabolism (Eastmond et al., 2002; Schluepmann et al., 2003; O'Hara et al., 2013). Most previous studies on trehalose metabolism only focus on trehalose, but neglect T6P (Almeida et al., 2005; Cortina and Culiáñez-Macià, 2005; Li et al., 2011). As indicated above, T6P is the precursor of trehalose in the biosynthetic pathway, which has lower content than trehalose in plants and thus is hardly detectable. For example, the concentrations of trehalose and T6P in Arabidopsis seedlings are 26.4 and $0.148 \mathrm{nmol} \mathrm{g}^{-1} \mathrm{FW}$, respectively (Van Houtte et al., 2013). This may be the most likely reason why many previous studies did not address T6P. 


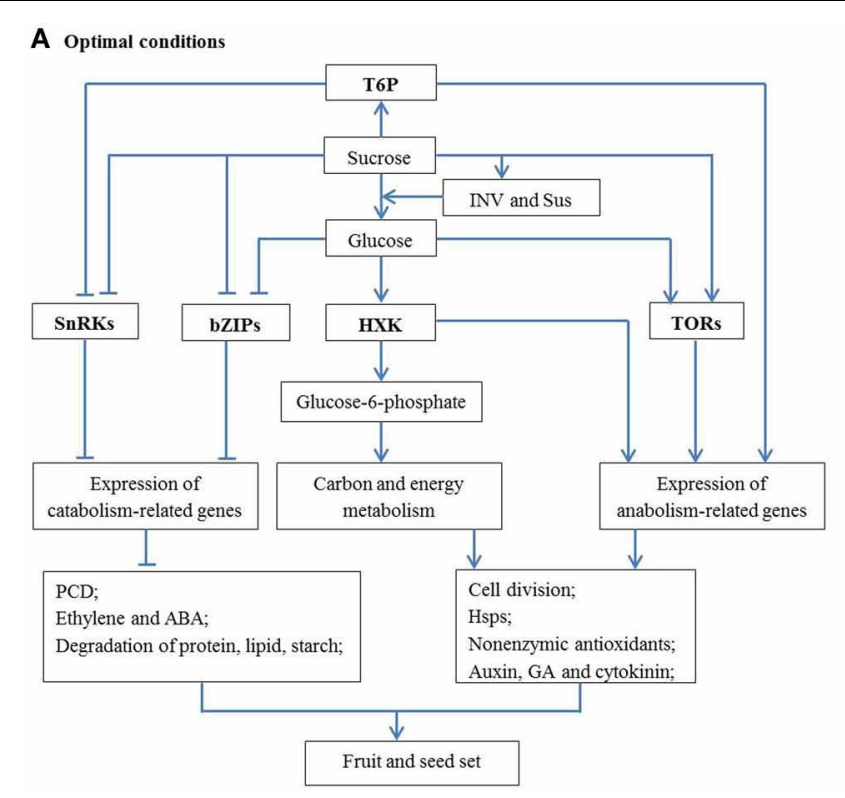

FIGURE 1 | A schematic network illustrating the mechanisms by which sugar metabolism and signaling regulate fruit and seed set under abiotic stresses. (A) Under optimal conditions with high sucrose availability, INV and Sus activities generate sufficient amount of hexoses (glucose) to activate cell division; to facilitate the production of non-enzymatic antioxidants and to inhibit PCD. On the other hand, T6P promotes biosynthetic process and represses the activity of a growth inhibitor, SnRKs. These features interact with hormonal signaling pathways

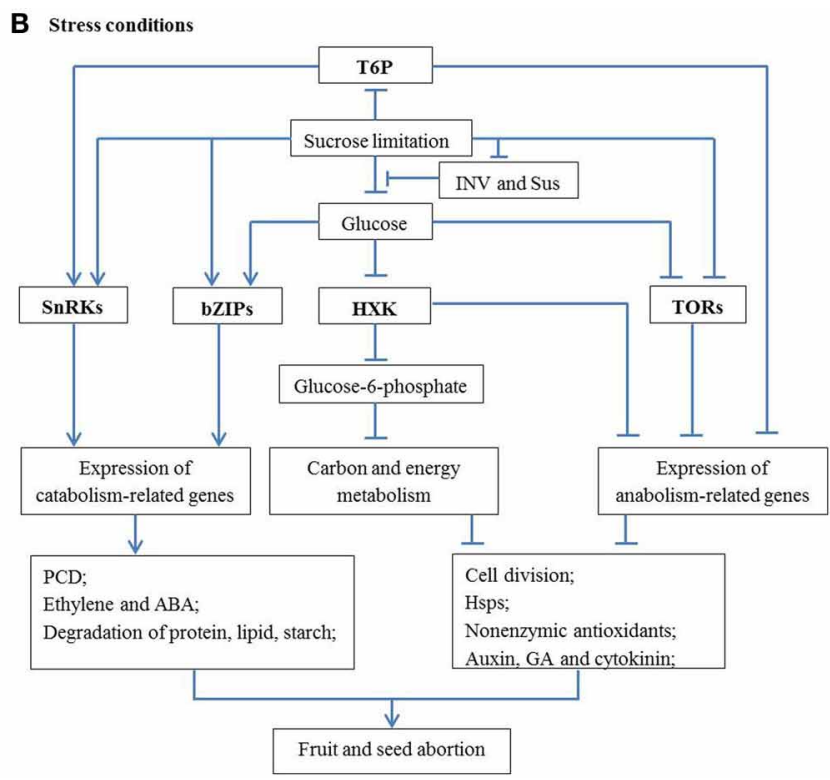

to allow seed and fruit set and subsequent growth to proceed. (B) The reverse applies under stress conditions where sugars are limited, and fruits and seeds abort. Arrow and T-type line represent the positive and negative effect, respectively. See text for more details. HSP, heat shock protein; HXK, hexokinase; INV, invertase; PCD, programmed cell death; Sus, sucrose synthase; T6P, trehalose-6-phosphate; TOR, target of rapamycin; SnRK, sucrose non-fermenting-1 (SNF1)-related protein kinases; bZIP, basic leucine-zipper proteins.
Trace amount of T6P in most plants implies that T6P may function as a sugar signal. Most recent studies showed decreased T6P level in Arabidopsis by knocking down the expression of AtTPS1 led to down-regulated expression of flower-triggering genes (e.g., FT and TSF) and thus a delay in flowering (Wahl et al., 2013). However, sugar availability (sucrose level) increased in the transgenic plants, indicating T6P acts as a signal to regulate the flower initiation of Arabidopsis (Wahl et al., 2013). Arabidopsis TPS (AtTPS1) protein interacted with the cell cycle kinase CDKA;1, suggesting the involvement of trehalose metabolism in cell cycle regulation. T6P may also participate in hormone signaling pathways. For example, increased T6P level down-regulated the expression of auxin/indole-3-acetic acid (Aux/IAA) and TIR1 in Arabidopsis, two important genes in auxin sensing and signaling (Paul et al., 2010).

A large body of data showed that trehalose metabolism plays important roles in plant resistance to diverse abiotic stresses ( $\mathrm{Li}$ et al., 2011). For example, the overexpression of the Arabidopsis TPS gene (AtTPS1) gene in tobacco increased tolerance to osmotic stress, drought, desiccation, and temperature stresses (Almeida et al., 2005). The introduction of yeast TPS1 gene into tomato enhanced plant tolerance to drought, salt and oxidative stress (Cortina and Culiáñez-Macià, 2005). Recently, native overexpressing of the rice TPS gene (OsTPS1) increased the tolerance of rice seedlings to salinity, drought and cold, possibly through up-regulating the expression of some abiotic stress-related genes including WSI18, RAB16C, HSP70, and ELIP (Li et al., 2011).
T6P has been proposed to acts as signal molecules to sense carbon availability (O'Hara et al., 2013), a possible mechanism for T6P to regulate plants growth and development in response to abiotic stress. T6P level in plants is positively related to sucrose levels (Schluepmann et al., 2004; Lunn et al., 2006; Martínez-Barajas et al., 2011). Thus, limited sugar availability under various abiotic stresses may reduce the content of T6P. Although no evidence showed there is a direct connection between T6P and the hexokinase-dependent sugar signaling pathway, Schluepmann et al. (2004) suggested there may be a link between T6P and sucrose non-fermenting related kinase-1 (SnRK1), which is known as a inhibitory factor of plant growth (Smeekens et al., 2010). T6P has an inhibitory effect on the activity of SnRK1 (Zhang et al., 2009; Paul et al., 2010). Thus, reduced T6P level under abiotic stresses may lead to an increase in SnRK1 activity and consequently inhibit the biosynthetic processes and plant growth.

\section{TARGET OF RAPAMYCIN}

TOR is one member of the family of phosphatidylinositol kinaserelated kinases, which is structurally and functionally conserved among organisms and found in nearly all eukaryotes. The TOR signaling has been well studied in fungi and animals (Smeekens et al., 2010) and plays important roles in cell growth and metabolism by integrating the response of cells to growth factors, nutrients, energy, and stress signals (Ahn et al., 2011). Although there is a scarcity of data on TOR in plants, recently it has been 
proposed to play an important role in plant development through coordinating development with nutrient availability including sugar (Robaglia et al., 2012). For example, AtTOR protein is indispensable for the normal plant and seed development in Arabidopsis (Deprost et al., 2007). Sugar abundance and starvation activate and inhibit the TOR kinase, respectively, followed by up- and down-regulation of energy-consuming related cellular processes, such as mRNA translation and cell proliferation, respectively (Robaglia et al., 2012). Rapamycin can effectively inhibit Arabidopsis TOR kinase activation by glucose and thus retards glucose-mediated root and leaf growth, indicating the central roles of glucose-TOR signaling in plant development (Xiong and Sheen, 2012). These authors further revealed that glucoseTOR signaling is another glucose signaling pathway in parallel with glucose-HXK and plays important roles in reactivation of the cell cycle in quiescent root meristems of Arabidopsis. This glucose-TOR signaling pathway is decoupled from hormone signaling and it was identified that E2Fa transcription factor is the downstream target of the glucose-TOR signaling pathway, which is responsible for the activation of cell cycle (S-phase) genes after its phosphorylation mediated by TOR kinase (Xiong et al., 2013). Sucrose can also activate this signaling pathway, while fructose can not (Xiong et al., 2013).

\section{SnRKs SIGNALING}

Sucrose non-fermenting-1(SNF1)-related protein kinases (SnRKs) is a homolog of the fungal SNF1, which is a global regulator of carbon metabolism in fungi (Coello et al., 2011). Plant SnRKs can be divided into three subgroups: SnRK1s, SnRK2s, and SnRK3s among which SnRK2s and SnRK3s emerged as a result of duplication during plant evolution. It is suggested that SnRK2s and SnRK3s allow plants to link metabolic and stress signaling (Halford and Hey, 2009), which does not occur in mammals and fungi (Coello et al., 2011). This feature gives SnRKs a potential role in regulation of plant responses to stresses. To deal with the sugar limitation (starvation) during stress conditions, plants take measures to limit anabolism and enhance catabolism to save energy and nutrients, in which SnRK act as central regulators (Guérinier et al., 2013). Limited sugar availability activates the activity of SnRKs (Cho et al., 2012), which act as inhibitors of gene expression involved in biosynthetic pathways (Baena-González et al., 2007; Baena-González and Sheen, 2008). At the same time, SnRK1 triggers starch degradation and mobilization under starvation conditions such as darkness (Avila et al., 2012).

In terms of responses to abiotic stresses, loss-of-function of SOS2, a SnRK3 gene in Arabidopsis, made plants more sensitive to salt stress, indicating SnRK3 is indispensable for salt tolerance in Arabidopsis (Liu et al., 2000). The knockout or overexpression of SRK2C, an osmotic-stress-activated SnRK2 protein kinase, led to drought-sensitive or tolerant phenotypes, respectively, in Arabidopsis via controlling the expression of stress-related genes (Umezawa et al., 2004). Previous studies showed SnRKs are involved in the ABA signaling pathway, which has been proposed to have a key role in plant tolerance to various abiotic stresses (e.g., salt stress, drought and heat stress) (Coello et al., 2011). For example, the overexpression of PKABA1, a SnRK2 gene from barley, mimicked the suppression of ABA to GA-inducible genes in the aleurone layer, indicating a possible role of PKABA1 in mediating the antagonism between ABA and GA (GómezCadenas et al., 1999). Arabidopsis triple mutant disruptive in three SnRK2s (i.e., SnRK2.2, 2.3, and 2.6) was completely insensitive to ABA treatment (Fujii and Zhu, 2009). SnRK1 has roles in regulation of cell cycle progression in plants. For instance, SnRK1 expression is high in leaf primordia of tomato, but low in meristems (Pien et al., 2001). Most recent studies showed that SnRK1 is involved in the regulation of cell cycle progression in Arabidopsis by controlling the phosphorylation of CDKI p27KIP1 homologs, AtKRP6 and AtKRP7 (Guérinier et al., 2013). The kinase activity of SnRK1 can be inhibited via the phosphorylation by protein kinase AvrPto-dependent Pto-interacting protein3 (Adi3), a suppressor of cell death, indicating SnRK participation in regulation of cell death (Avila et al., 2012).

\section{bZIPs}

The basic leucine-zipper (bZIP) proteins are a large family of multifunctional transcription factors which are characterized by a basic DNA binding region and a leucine-zipper coiled-coil motif in eukaryotes (Reinke et al., 2013). Emerging evidence showed that bZIPs play roles in sugar signaling. It has been proposed that Arabidopsis S1 class bZIPs are transducers of sucrose-specific signals (Weltmeier et al., 2009). At the same time, bZIP11 is also a potential target of SnRK1 (O'Hara et al., 2013).

bZIPs can perceive the variation in sugar status of plants and regulate the profile of gene expression, and thus plant response to internal and external signals (Kang et al., 2010). High sugar availability usually down-regulates the activity of bZIP. For example, sucrose inhibited the translation of AtbZIP11 mRNA in Arabidopsis (Rook et al., 1998). Glucose repressed the transcription of AtbZIP1 in Arabidopsis via a HK-dependent pathway (Kang et al., 2010). However, glucose repressed the transcription of AtbZIP63 in Arabidopsis in an HK-independent way (Matiolli et al., 2011). Furthermore, the full repression of AtbZIP63 expression by glucose at a high concentration (6\%) required the participation of ABA, indicating the involvement of AtbZIP63 in the glucose-ABA interaction network (Matiolli et al., 2011). Thus, it appears that the mechanism of the bZIP inhibition by sugar is complex and varies with changes in sugar species and levels.

Similar to SnRKs, bZIPs also act as growth inhibitory regulators (Smeekens et al., 2010). For example, the overexpression of AtbZIP1 and AtbZIP11 halted the seedling growth of Arabidopsis (Hanson et al., 2008; Kang et al., 2010). The growth inhibition from overexpression of bZIP11 can be relieved by T6P accumulation from trehalose feeding (Schluepmann et al., 2004; Delatte et al., 2011). bZIPs are known to be involved in nutrient (e.g., sugar) and/or stress signaling (Kang et al., 2010; Smeekens et al., 2010; O'Hara et al., 2013) to gain a homeostasis between plant growth and nutrient availability, especially under stress conditions. Plenty of evidence has shown that bZIPs play an important role in the response of plants to various stresses. For example, Arabidopsis seedlings overexpressing a pepper bZIP (CAbZIP1) showed enhanced resistance to drought and salt stresses, but the phenotype was dwarfed under optimal condition 
(Lee et al., 2006), indicating the enhanced stress tolerance may be produced at the cost of normal development. Arabidopsis seedlings expressing soybean bZIP proteins (GmbZIP44, GmbZIP62, or GmbZIP78) exhibited higher tolerance to salt and cold stress, possibly through negative interaction with ABA signaling (Liao et al., 2008). However, rice seedlings overexpressing OsbZIP52 showed significantly increased sensitivity to cold and drought stress (Liu et al., 2012).

As detailed above, sugar-derived signaling systems (T6P, TOR, SnRK, and bZIP) play important roles in plant responses to abiotic stresses through maintaining the homoeostasis between sugar availability and plant metabolism (Smeekens et al., 2010; Robaglia et al., 2012). Although most of these studies focused on the vegetative stage, the understanding and manipulation of these signaling systems provide new potential options for improvement of seed and fruit set under abiotic stresses including heat and drought.

\section{A POSSIBLE REGULATORY NETWORK UNDERLYING SUGAR-MEDIATED CONTROL OF FRUIT AND SEED SET}

The analyses above allow a possible regulatory network to be formulated about how sucrose metabolism and signaling regulate fruit and seed set under abiotic stresses (Figure 1). Under optimal conditions, sucrose import and its degradation by INV or Sus produce adequate hexoses for development of fruit and seed (or other sink organs). Glucose signaling can facilitate cell division directly or through promoting the response of growthrelated hormones (auxin, GA, and cytokinin) and inhibiting senescence-related hormone pathways, hence allowing fruit and seed set (Figure 1A). At the same time, T6P and TORs signaling networks can promote plant growth through up-regulating the expression of anabolism-related genes, whereas SnRKs and bZIP signaling networks with growth inhibitory effects are restrained under optimal conditions. On the other hand, glucose could enter the oxidative pentose phosphate pathway to provide carbon skeletons and energy for biosynthesis of Hsps and non-enzymic antioxidants, thereby preventing oxidative stress and fruit and seed abortion. However, the reverse applies under stress conditions (Figure 1B) where a decreased glucose level could lead to hormonal imbalance, excessive ROS and insufficient Hsps, which may arrest cell division and trigger PCD. Furthermore, sugar limitation inhibits activities of T6P and TOR signaling, but induces activities of SnRKs and bZIPs signaling which can also inhibit

\section{REFERENCES}

Almeida, A. M., Villalobos, E., Araújo, S. S., Leyman, B., Van Dijck, P., Alfaro-Cardoso, L., et al. (2005). Transformation of tobacco with an Arabidopsis thaliana gene involved in trehalose biosynthesis increases tolerance to several abiotic stresses. Euphytica 146, 165-176. doi: 10.1007/s10681-005-7080-0

Andersen, M. N., Asch, F., Wu, Y., Jensen, C. R., Naested, H., Mogensen, V. O., et al. (2002). Soluble invertase expression is an early target of drought stress during the critical, abortion sensitive phase of young ovary development in maize. Plant Physiol. 130, 591-604. doi: 10.1104/pp.005637

Andriunas, F. A., Zhang, H. M., Xue, X., Offler, C. E., McCurdy, D. W., and Patrick, J. W. (2012). Reactive oxygen species form part of a regulatory pathway initiating transdifferentiation of epidermal transfer cells in Vicia faba cotyledons. J. Exp. Bot. 63, 3617-3630. doi: 10.1093/jxb/ers029

Ahn, C. S., Han, J. A., Lee, H. S., Lee, S., and Pai, H. S. (2011). The PP2A

cell proliferation through suppressing expression of biosynthetic genes. Together, these biochemical and molecular features could lead to seed and fruit abortion or stunted growth under stress conditions (Figure 1B).

\section{CONCLUSION AND PERSPECTIVES}

A large body of evidence indicates that sugar metabolism and signaling play important regulatory roles in fruit and seed set and their subsequent development. It is clear that more direct molecular evidence is required to dissect the causal and consequential relationship between changes in sugar metabolism and other biochemical processes and associated phenotype. For instance, although it is well known that glucose metabolism affects hormone levels, it remains to be determined whether the impact is exerted through modulating hormonal sensing and signaling or metabolism and how different hormones coordinate to regulate fruit and seed set under stresses. Second, experimental evidence is still lacking as to whether, and to what extent, biosynthesis of Hsps and maintenance of ROS homeostasis are dependent on sugar metabolism and signaling. Third, previous studies mostly focused on the down-regulation of sugar metabolism, which often has multiple detrimental effects on phenotype and consequently masks the key changes in reproductive development (Boyer and McLaughlin, 2007; Zanor et al., 2009). Little is known about what will happen to fruit and seed development under abiotic stress if key sugar metabolic enzymes, INV and Sus, are up-regulated. Fourth, mounting evidence shows that T6P, TOR, SnRK, and bZIP signaling networks play central roles in plant development through integrating sugar availability and developmental programmes to optimize plant performance. However, no sensor has been identified in perception of sugar status in these networks and the molecular functions and the regulatory mechanisms of them are still largely obscure. Thus, more work needs to be dedicated to this field. Finally, the global analysis of stress responsive regulatory pathways by using new techniques such as RNAseq will help us to understand the signaling cascades by which sugar metabolism and signaling regulate fruit and seed response to heat and drought.

\section{ACKNOWLEDGMENTS}

Yong-Hua Liu is a recipient of a $\mathrm{PhD}$ scholarship from the University of Newcastle. We thank Australian Research Council for financial support (ARC DP110104931 and DP120104148).

regulatory subunit Tap46, a component of the TOR signaling pathway, modulates growth and metabolism in plants. Plant Cell 23, 185-209. doi: 10.1105/tpc.110.074005

Avila, J., Gregory, O. G., Su, D., Deeter, T. A., Chen, S., Silva-Sanchez, C., et al. (2012). The $\beta$-subunit of the SnRK1 complex is phosphorylated by the plant cell death suppressor Adi3. Plant Physiol. 159, 1277-1290. doi: 10.1104/pp.112. 198432

Baena-González, E., Rolland, F., Thevelein, J. M., and Sheen, Jen.
(2007). A central integrator of transcription networks in plant stress and energy signalling. Nature 448, 938-942.

Baena-González, E., and Sheen, J. (2008). Convergent energy and stress signaling. Trends Plant Sci. 13, 474-482. doi: 10.1016/j.tplants. 2008.06.006

Baldet, P., Hernould, M., Laporte, F., Mounet, F., Just, D., Mouras, A., et al. (2006). The expression of cell proliferation-related genes in early developing flowers is affected by a fruit load reduction in tomato 
plants. J. Exp. Bot. 57, 961-970. doi: 10.1093/jxb/eri082

Barnabás, B., Jager, K., and Feher, A. (2008). The effect of drought and heat stress on reproductive processes in cereals. Plant Cell Environ. 31, 11-38.

Battisti, D. S., and Naylor, R. L. (2009). Historical warnings of future food insecurity with unprecedented seasonal heat. Science 323, 240-244. doi: 10.1126/science. 1164363

Beddington, J. (2010). Food security: contributions from science to a new and greener revolution. Philos. Trans. R. Soc. Lond. B Biol. Sci. 365, 61-71. doi: 10.1098/rstb. 2009.0201

Beere, H. M. (2004). "The stress of dying": the role of heat shock proteins in the regulation of apoptosis. J. Cell Sci. 117, 2641-2651. doi: $10.1242 /$ jcs. 01284

Bienert, G. P., Møller, A. L. B., Kristiansen, K. A., Schulz, A., Møller, I. M., Schjoerring, J. K., et al. (2007). Specific aquaporins facilitate the diffusion of hydrogen peroxide across membranes. J. Biol. Chem. 282, 1183-1192. doi: 10.1074/jbc.M603761200

Blanke, M. M., and Lenz, F. (1989). Fruit photosynthesis. Plant Cell Environ. 12, 31-46. doi: 10.1111/j. 1365-3040.1989.tb01914.x

Bolouri-Moghaddam, M., Le Roy, K., Xiang, L., Rolland, F., and Van den Ende, W. (2010). Sugar signalling and antioxidant network connections in plant cells. FEBS J. 277, 2022-2037. doi: 10.1111/j.1742-4658.2010.07633.x

Boyer, J. S., and McLaughlin, J. E. (2007). Functional reversion to identify controlling genes in multigenic responses: analysis of floral abortion. J. Exp. Bot. 58, 267-277. doi: $10.1093 /$ jxb/erl177

Chao, Q., Rothenberg, M., Solano, R., Roman, G., Terzaghi, W., and Ecker, J. R. (1997). Activation of the ethylene gas response pathway in Arabidopsis by the nuclear protein ETHYLENE-INSENSITIVE 3 and related proteins. Cell 89, 1133-1144. doi: 10.1016/S0092-867480300-1

Cho, Y. H., Hong, J. W., Kim, E. C., and Yoo, S. D. (2012). Regulatory functions of SnRK1 in stressresponsive gene expression and in plant growth and development. Plant Physiol. 158, 1955-1964. doi: 10.1104/pp.111.189829

Cho, Y. H., and Yoo, S. D. (2011). Signaling role of fructose mediated by FINS1/FBP in Arabidopsis thaliana. PLoS Genet. 7:1001263. doi: 10.1371/journal.pgen.1001263
Coello, P., Hey, S. J., and Halford, N. G. (2011). The sucrose nonfermenting-1-related (SnRK) family of protein kinases: potential for manipulation to improve stress tolerance and increase yield. J. Exp. Bot. 62, 883-893. doi: 10.1093/jxb/erq331

Cortina, C., and Culiáñez-Macià, F. A. (2005). Tomato abiotic stress enhanced tolerance by trehalose biosynthesis. Plant Sci. 169, 75-82.

Couée, I., Sulmon, C., Gouesbet, G., and El Amrani, A. (2006). An involvement of soluble sugars in reactive oxygen species balance and responses to oxidative stress in plants. J. Exp. Bot. 57, 449-459. doi: 10.1093/jxb/erj027

Dat, J. F., Lopez-Delgado, H., Foyer C. H., and Scott, I. M. (1998). Parallel changes in $\mathrm{H}_{2} \mathrm{O}_{2}$ and catalase during thermotolerance induced by salicylic acid or heat acclimation in mustard seedlings. Plant Physiol. 116, 1351-1357. doi 10.1104/pp.116.4.1351

Davies, P. J. (2010). "The plant hormones: their nature, occurrence, and functions" in Plant Hormones: Biosynthesis, Signal Transduction, Action! ed P. Davies (Dordrecht: Springer Press), 1-15.

Delatte, T. L., Sedijani, P., Kondou, Y., Matsui, M., de Jong, G. J., Somsen, G. W., et al. (2011). Growth arrest by trehalose-6-phosphate: an astonishing case of primary metabolite control over growth by way of the SnRK1 signaling pathway. Plant Physiol. 157, 160-174. doi: 10.1104/pp.111.180422

Deprost, D., Yao, L., Sormani, R., Moreau, M., Leterreux, G., Nicolai, M., et al. (2007). The Arabidopsis TOR kinase links plant growth, yield, stress resistance and mRNA translation. EMBO Rep. 8, 864-870. doi: 10.1038/sj.embor.7401043

Dewitte, W., and Murray, J. A. H. (2003). The plant cell cycle. Annu. Rev. Plant Biol. 54, 235-264. doi: $\quad 10.1146 /$ annurev.arplant.54. 031902.134836

Dorcey, E., Urbez, C., Blázquez, M. A., Carbonell, J., and Perez-Amador, M. A. (2009). Fertilization-dependent auxin response in ovules triggers fruit development through the modulation of gibberellin metabolism in Arabidopsis. Plant J. 58, 318-332. doi: 10.1111/j.1365313X.2008.03781.x

Döös, B. R. (2002). Population growth and loss of arable land. Glob. Environ. Change 12, 303-311. doi: 10.1016/S0959-378000043-2

Dugas, D. V., and Bartel, B. (2008) Sucrose induction of Arabidopsis
miR398 represses two $\mathrm{Cu} / \mathrm{Zn}$ superoxide dismutases. Plant Mol. Biol. 67, 403-417. doi: 10.1007/s11103008-9329-1

Eastmond, P. J., Van Dijken, A. J. H., Spielman, M., Kerr, A., Tissier, A., Dickinson, H. G., et al. (2002). Trehalose-6-phosphate synthase 1 , which catalyses the first step in trehalose synthesis, is essential for Arabidopsis embryo maturation. Plant J. 29, 225-235. doi 10.1046/j.1365-313x.2002.01220.x

Egli, D. B. (2010). SOYPOD: a model of fruit set in soybean. Agron. J. 102, 39-47. doi 10.2134/agronj2009.0222

Ehness, R., and Roitsch, T. (1997). Coordinated induction of mRNAs for extracellular invertase and a glucose transporter in Chenopodium rubrum by cytokinins. Plant $J$. 11, 539-548. doi: 10.1046/j.1365313X.1997.11030539.x

Fedoroff, N. V., Battisti, D. S. Beachy, R. N., Cooper, P. J. M., Fischhoff, D. A., Hodges, C. N., et al. (2010). Radically rethinking agriculture for the 21st century. Science 327, 833-834. doi 10.1126/science.1186834

Finka, A., Mattoo, R. U. H., and Goloubinoff, P. (2011). Metaanalysis of heat- and chemically upregulated chaperone genes in plant and human cells. Cel Stress Chaperones 16, 15-31. doi: 10.1007/s12192-010-0216-8

Finka, A., Quendet, A. F. H., Maathuis, F. J. M., Saidi, Y., and Goloubinoff, P. (2012). Plasma membrane cyclic nucleotide gated calcium channels control land plant thermal sensing and acquired thermotolerance. Plant Cell 24, 3333-3348. doi 10.1105/tpc.112.095844

Foulkes, M. J., Slafer, G. A., Davies, W. J., Berry, P. M., Sylvester-Bradley, R., Martre, P., et al. (2011). Raising yield potential of wheat. III. optimizing partitioning to grain while maintaining lodging resistance. J. Exp. Bot. 62, 469-486. doi: $10.1093 / \mathrm{jxb} / \mathrm{erq} 300$

Foyer, C. H., and Noctor, G. (2005) Oxidant and antioxidant signaling in plants: a re-evaluation of the concept of oxidative stress in a physiological context. Plant Cell Environ. 28, 1056-1071. doi: 10.1111/j.13653040.2005.01327.x

Fujii, H., and Zhu, J. K. (2009). Arabidopsis mutant deficient in 3 abscisic acid-activated protein kinases reveals critical roles in growth, reproduction, and stress. Proc. Natl. Acad. Sci. U.S.A. 1106, 8380-8385. doi: 10.1073/pnas.0903144106
Garrity, D. P., Akinnifesi, F. K., Ajayi, O. C., Weldesemayat, S. G., Mowo, J. G., Kalinganire, A., et al. (2010). Evergreen agriculture: a robust approach to sustainable food security in africa. Food Secur. 2, 197-214. doi: 10.1007/s12571-010-0070-7

Ghiglione, H. O., Gonzalez, F. G., Serrago, R., Maldonado, S. B., Chilcott, C., Curá, J. A., et al. (2008). Autophagy regulated by day length determines the number of fertile florets in wheat. Plant J. 55, 1010-1024. doi: 10.1111/j.1365-313X.2008.03570.x

Gillaspy, G., Ben-David, H., and Gruissem, W. (1993). Fruits: a developmental perspective. Plant Cell 5, 1439-1451.

Godfray, H. C. J., Beddington, J. R. Crute, I. R., Haddad, L., Lawrence, D., Muir, J. F., et al. (2010). Food security: the challenge of feeding 9 billion people. Science 327, 812-818. doi: 10.1126/science. 1185383

Gómez-Cadenas, A., Verhey, S. D., Holappa, L. D., Shen, Q., Ho, T.-H. D., and Walker-Simmons, M. K. (1999). An abscisic acidinduced protein kinase, PKABA1, mediates abscisic acid-suppressed gene expression in barley aleurone layers. Proc. Natl. Acad. Sci. U.S.A. 96, 1767-1772. doi: 10.1073/pnas.96.4.1767

Guérinier, T., Millan, L., Crozet, P., Oury, C., Rey, F., Valot, B., et al. (2013). Phosphorylation of p27KIP1 homologs KRP6 and 7 by SNF1-related protein kinase-1 links plant energy homeostasis and cell proliferation. Plant J. doi: $10.1111 /$ tpj. 12218

Halford, N. G., and Hey, S. J. (2009). SNF1-related protein kinases (SnRKs) act within an intricate network that links metabolic and stress signalling in plants. Biochem. J. 419, 247-259. doi: 10.1042/BJ20082408

Hanson, J., Hanssen, M., Wiese, A., Hendriks, M. M., and Smeekens, S. (2008). The sucrose regulated transcription factor bZIP11 affects amino acid metabolism by regulating the expression of ASPARAGINE SYNTHETASE1 and PROLINE DEHYDROGENASE2. Plant J. 53, 935-949. doi: 10.1111/j.1365-313X.2007.03385.x

Hedhly, A., Hormaza, J. I., and Herrero, M. (2008). Global warming and plant sexual reproduction. Trends Plant Sci. 14, 30-36. doi: 10.1016/j.tplants.2008.11.001

Ho, L. C. (1988). Metabolism and compartmentation of imported sugars in sink organs in relation to sink strength. Annu. Rev. Plant Physiol. Plant Mol. Biol. 39, 355-378. 
doi: 10.1146/annurev.pp.39.060188. 002035

Horváth, I., Glatz, A., Varvasovszki, V., Török, Z., Páli, T., Balogh, G., et al. (1998). Membrane physical state controls the signaling mechanism of the heat shock response in Synechocystis PCC 6803: Identification of $h s p 17$ as a "fluidity gene". Proc. Natl. Acad. Sci. U.S.A. 95, 3513-3518. doi: 10.1073/pnas.95.7.3513

Ji, X., Dong, B., Shiran, B., Talbot, M. J., Edlington, J. E., Hughes, T., et al. (2011). Control of abscisic acid catabolism and abscisic acid homeostasis is important for reproductive stage stress tolerance in cereals. Plant Physiol. 156, 647-662. doi: 10.1104/pp.111.176164

Jia, H., Wang, Y., Sun, M., Li, B., Han, Y., Zhao, Y., et al. (2013). Sucrose functions as a signal involved in the regulation of strawberry fruit development and ripening. New Phytol. 198, 453-465. doi: 10.1111/nph.12176

Jin, Y., Ni, D. A., and Ruan, Y. L. (2009). Posttranslational elevation of cell wall invertase activity by silencing its inhibitor in tomato delays leaf senescence and increases seed weight and fruit hexose level. Plant Cell 21, 2072-2089. doi: 10.1105/tpc.108. 063719

Kakumanu, A., Ambavaram, M. M. R., Klumas, C., Krishnan, A., Batlang, U., Myers, E., et al. (2012). Effects of drought on gene expression in maize reproductive and leaf meristem tissue revealed by RNA-Seq. Plant Physiol. 160, 846-867. doi: 10.1104/pp.112.200444

Kang, S. G., Price, J., Lin, P. C., Hong, J. C., and Jang, J. C. (2010). The Arabidopsis bZIP1 transcription factor is involved in sugar signaling, protein networking, and DNA binding. Mol. Plant 3, 361-373. doi: $10.1093 / \mathrm{mp} / \mathrm{ssp} 115$

Kim, J. Y., Mahé, A., Brangeon, J., and Prioul, J. L. (2000). A maize vacuolar invertase, $I V R_{2}$, is induced by water stress: organ/tissue specificity and diurnal modulation of expression. Plant Physiol. 124, 71-84. doi: 10.1104/pp.124.1.71

Koch, K. E. (2004). Sucrose metabolism: regulatory mechanisms and pivotal roles in sugar sensing and plant development. Curr. Opin. Plant Biol. 7, 235-246. doi: 10.1016/j.pbi.2004.03.014

Kovtun, Y., Chiu, W. L., Tena, G., and Sheen, J. (2000). Functional analysis of oxidative stress-activated mitogen-activated protein kinase cascade in plants. Proc. Natl. Acad.
Sci. U.S.A. 97, 2940-2945. doi: 10.1073/pnas.97.6.2940

Laloi, C., Apel, K., and Danon, A. (2004). Reactive oxygen signaling: the latest news. Curr. Opin. Plant Biol. 7, 323-328. doi: 10.1016/j.pbi.2004.03.005

Lara, M. E. B., Garcia, M. C. G., Fatima, T., Ehneb, R., Lee, T. K., Proels, R., et al. (2004). Extracellular invertase is an essential component of cytokinin-mediated delay of senescence. Plant Cell 16, 1276-1287. doi: 10.1105/tpc.018929

LeClere, S., Schmelz, E. A., and Chourey, P. S. (2010). Sugar levels regulate tryptophandependent auxin biosynthesis in developing maize kernels. Plant Physiol. 153, 306-318. doi: 10.1104/pp.110.155226

Lee, S. C., Choi, H. W., Hwang, I. S., Choi, D. S., and Hwang, B. K. (2006). Functional roles of the pepper pathogen-induced bZIP transcription factor, CAbZIP1, in enhanced resistance to pathogen infection and environmental stresses. Planta 224, 1209-1225. doi: 10.1007/s00425-006-0302-4

Li, H. W., Zang, B. S., Deng, X. W., and Wang, X. P. (2011). Overexpression of the trehalose-6phosphate synthase gene OsTPS1 enhances abiotic stress tolerance in rice. Planta 234, 1007-1018. doi: 10.1007/s00425-011-1458-0

Li, Z., Palmer, W. M., Martin, A. P., Wang, R., Rainsford, F., Jin, Y., et al. (2012). High invertase activity in tomato reproductive organs correlates with enhanced sucrose import into, and heat tolerance of, young fruit. J. Exp. Bot. 63, 1155-1166. doi: 10.1093/jxb/err329

Liao, Y., Zou, H. F., Wei, W., Hao, Y. J., Tian, A. G., Huang, J., et al. (2008). Soybean GmbZIP44, GmbZIP62 and GmbZIP78 genes function as negative regulator of ABA signaling and confer salt and freezing tolerance in transgenic Arabidopsis. Planta 228, 225-240.

Liu, J., Ishitani, M., Halfter, U., Kim, C. S., and Shu, J. K. (2000). The Arabidopsis thaliana SOS2 gene encodes a protein kinase that is required for salt tolerance. Proc. Natl. Acad. Sci. U.S.A. 97, 3730-3734

Liu, C., Wu, Y., and Wang, X. (2012). bZIP transcription factor OsbZIP52/RISBZ5: a potential negative regulator of cold and drought stress response in rice. Planta 235, 1157-1169.

Liu, J., Wang, X., Hu, Y., Hu, W., and Bi, Y. (2013). Glucose-6-phosphate dehydrogenase plays a pivotal role in tolerance to drought stress in soybean roots. Plant Cell Rep. 32, 415-429. doi: 10.1007/s00299-0121374-1

Liu, F., Jensen, C. R., and Andersen, M. N. (2004). Drought stress effect on carbohydrate concentration in soybean leaves and pods during early reproductive development, its implication in altering pod set. Field Crops Res. 86, 1-13. doi: 10.1016/S0378-429000165-5

Lunn, J. E., Feil, R., Hendriks, J. H. M., Gibon, Y., Morcuende, R., Osuna, D., et al. (2006). Sugar-induced increases in trehalose 6-phosphate are correlated with redox activation of ADPglucose pyrophosphorylase and higher rates of starch synthesis in Arabidopsis thaliana. Biochem. J. 397(Pt 1), 139-148

Lytovchenko, A., EickmeierPons, C., Osorio, S., Szecowka, M., Lehmberg, K., Arrivault, S., et al. (2011). Tomato fruit photosynthesis is seemingly unimportant in primary metabolism and ripening but plays a considerable role in seed development. Plant Physiol. 157, 1650-1663. doi: 10.1104/pp.111.186874

Macgregor, D. R., Deak, K. I., Ingram, P. A., and Malamy, J. E. (2008). Root system architecture in Arabidopsis grown in culture is regulated by sucrose uptake in the aerial tissues. Plant Cell 20, 2643-2660. doi: 10.1105/tpc.107.055475

Malik, M. K., Slovin, J. P., Hwang, C. H., and Zimmerman, J. L. (1999). Modified expression of a carrot small heat shock protein gene, $h s p 17.7$, results in increased or decreased thermotolerance double dagger. Plant J. 20, 89-99. doi: 10.1046/j.1365-313X.1999.00581.x

Martínez-Barajas, E., Delatte, T., Schluepmann, H., de Jong, G. J., Somsen, G. W., Nunes, C., et al. (2011). Wheat grain development is characterized by remarkable trehalose 6-phosphate accumulation pregrain filling: tissue distribution and relationship to SNF1-related protein kinasel activity. Plant Physiol. 156, 373-381. doi: 10.1104/pp.111.174524

Matiolli, C. C., Tomaz, J. P., Duarte, G. T., Prado, F. M., Del Bem, L. E. V., Silveira, A. B., et al. (2011). The Arabidopsis bZIP gene AtbZIP63 is a sensitive integrator of transient abscisic acid and glucose signals. Plant Physiol. 157, 692-705. doi: 10.1104/pp.111.181743

McLaughlin, J. E., and Boyer, J. S. (2004a). Glucose localisation in maize ovaries when kernel number decreases at low water potential and sucrose is fed to the stems. Ann. Bot. 94, 75-86.

McLaughlin, J. E., and Boyer, J. S. (2004b). Sugar-responsive gene expression, invertase activity, and senescence in aborting maize ovaries at low water potentials. Ann. Bot. 94, 675-689.

Miller, M. E., and Chourey, P. S. (1992). The maize invertase-deficient minature-1 seed mutation is associated with aberrant pedicel and endosperm development. Plant Cell 4, 297-305.

Mishra, B. S., Singh, M., Aggrawal, P., and Laxmi, A. (2009). Glucose and auxin signalling interaction in controlling Arabidopsis thaliana seedlings root growth and development. PLoS ONE 4:e4502. doi: 10.1371/journal.pone.0004502

Mittler, R. (2002). Oxidative stress, antioxidants and stress tolerance. Trends Plant Sci. 7, 405-410. doi: 10.1016/S1360-138502312-9

Mittler, R., and Blumwald, E. (2010). Genetic engineering for modern agriculture: challenges and perspectives. Annu. Rev. Plant Biol. 61, 443-462. doi: 10.1146/annurevarplant-042809-112116

Mittler, R., Finka, A., and Goloubinoff, P. (2012). How do plants feel the heat. Trends Biochem. Sci. 37, 118-125

Moore, B., Zhou, L., Rolland, F., Hall, Q., Cheng, W. H., Liu, Y. X., et al. (2003). Role of the Arabidopsis glucose sensor HXK1 in nutrient, light, and hormonal signaling. Science 300, 332-336. doi: 10.1126/science. 1080585

Munné-Bosch, S., Queval, G., and Foyer, C. H. (2013). The impact of global change factors on redox signaling underpinning stress tolerance. Plant Physiol. 161, 5-19. doi: 10.1104/pp.112.205690

O'Hara, L. E., Paul, M. J., and Wingler, A. (2013). How do sugars regulate plant growth and development. New insight into the role of trehalose-6-phosphate. Mol. Plant. 6, 261-274. doi: 10.1093/mp/sss120

Oktyabrsky, O. N., and Smirnova, G. V. (2007). Redox regulation of cellular functions. Biochemistry (Mosc.) 72, 132-145. doi: 10.1134/S0006297907020022

Oliver, S. N., Dennis, E. S., and Dolferus, R. (2007). ABA regulates apoplastic sugar transport and is a potential signal for coldinduced pollen sterility in rice. Plant Cell Physiol. 48, 1319-1330. doi: $10.1093 / \mathrm{pcp} / \mathrm{pcm} 100$

Patrick, J. W., and Stoddard, F. L. (2010). Physiology of flowering and grain filling in faba bean. 
Field Crops Res. 115, 234-242. doi: 10.1016/j.fcr.2009.06.005

Paul, M. J., Jhurreea, D., Zhang, Y., Primavesi, L. F., Delatte, T., Schluepmann, H., et al. (2010). Upregulation of biosynthetic processes associated with growth by trehalose 6-phosphate. Plant Signal. Behav. 5, 1-7. doi: 10.4161/psb.5.4.10792

Pien, S., Wyrzykowska, J., and Fleming, A. J. (2001). Novel marker genes for early leaf development indicate spatial regulation of carbohydrate metabolism within the apical meristem. Plant J. 25, 663-674. doi: 10.1046/j.1365-313x.2001.01002.x

Pinheiro, C., António, C., Ortuño, M. F., Dobrev, P. I., Hartung, W., and Thomas-Oates, J. (2011). Initial water deficit effects on Lupinus albus photosynthetic performance, carbon metabolism, and hormonal balance: metabolic reorganization prior to early stress responses. J. Exp. Bot. 62, 4965-4974.

Queitsch, C., Hong, S. W., Vierling, E., and Lindquist, S. (2000). Heat shock protein 101 plays a crucial role in thermotolerance in Arabidopsis. Plant Cell 12, 479-492.

Rampino, P., Mita, G., Fasano, P., Borrelli, G. M., Aprile, A., Dalessandro, G., et al. (2012). Novel durum wheat genes up-regulated in response to a combination of heat and drought stress. Plant Physiol. Biochem. 56, 72-78. doi: 10.1016/j.plaphy.2012.04.006

Reinke, A. W., Baek, J., Ashenberg, O., and Keating, A. E. (2013). Networks of bZIP protein-protein interactions diversified over a billion years of evolution. Science 340, 730-734.

Robaglia, C., Thomas, M., and Meyer, C. (2012). Sensing nutrient and energy status by SnRK1 and TOR kinases. Curr. Opin. Plant Biol. 15, 301-307. doi: 10.1016/j.pbi.2012.01.012

Rook, F., Gerrits, N., Kortstee, A., vanKampen, M., Borrias, M., Weisbeek, P., et al. (1998). Sucrose-specific signalling represses translation of the Arabidopsis ATB2 bZIP transcription factor gene. Plant J. 15, 253-263. doi: 10.1046/j.1365-313X.1998.00205.x

Ross-Ibarra, J., Morrell, P. L., and Gaut, B. S. (2007). Plant domestication, a unique opportunity to identify the genetic basis of adaptation. Proc. Natl. Acad. Sci. U.S.A. 104, 8641-8648. doi: 10.1073/pnas.0700643104

Ruan, Y. L., Jin, Y., Li, G. J., Yang, Y. J., and Boyer, J. S. (2010). Sugar input, metabolism and signaling mediated by invertase: roles in development, yield potential and response to drought and heat. Mol. Plant 3, 942-955. doi: 10.1093/mp/ssq044

Ruan, Y. L. (2012). Signaling role of sucrose metabolism in development. Mol. Plant 5, 763-765. doi: $10.1093 / \mathrm{mp} / \mathrm{sss} 046$

Ruan, Y. L., Patrick, J. W., Bouzayen, M., Osorio, S., and Fernie, A. R. (2012). Molecular regulation of seed and fruit set. Trends Plant Sci. 17, 656-665. doi: 10.1016/j.tplants.2012.06.005

Sairanen, I., Novák, O., Pìnèík, A., Ikeda, Y., Jones, B., Sandberg, G., et al. (2012). Soluble carbohydrates regulate auxin biosynthesis via PIF proteins in Arabidopsis. Plant Cell 24, 4907-4916. doi: 10.1105/tpc.112.104794

Sangwan, V., Orvar, B. L., Beyerly, J., Hirt, H., and Dhindsa, R. S. (2002). Opposite changes in membrane fluidity mimic cold and heat stress activation of distinct plant MAP kinase pathways. Plant J. 31, 629-638. doi: 10.1046/j.1365-313X.2002.01384.x

Schluepmann, H., Pellny, T., van Dijken, A., Smeekens, S., and Paul, M. (2003). Trehalose 6-phosphate is indispensible for carbohydrate utilization and growth in Arabidopsis thaliana. Proc. Natl. Acad. Sci. U.S.A. 100, 6849-6854

Schluepmann, H., van Dijken, A., Aghdasi, M., Wobbes, B., Paul, M., and Smeekens, S. (2004). Trehalose mediated growth inhibition of Arabidopsis seedlings is due to trehalose-6-phosphate accumulation. Plant Physiol. 135, 879-890. doi: 10.1104/pp.104.039503

Setter, T. L., Yan, J., Warburton, M., Ribaut, J. M., Xu, Y., Sawkins, M., et al. (2011). Genetic association mapping identifies single nucleotide polymorphisms in genes that affect abscisic acid levels in maize floral tissues during drought. J. Exp. Bot. 62, 701-716. doi: 10.1093/jxb/erq308

Sharma, S. K., De los Rios, P., Christen, P., Lustig, A., and Goloubinoff, P. (2010). The kinetic parameters and energy cost of the Hsp70 chaperone as a polypeptide unfoldase. Nat. Chem. Biol. 6, 914-920. doi: 10.1038/nchembio.455

Sinkevich, M. S., Naraykina, N. V., and Trunova, T. I. (2010). Involvement of sugars in the antioxidant defense against paraquat-induced oxidative stress in potato transformed with yeast invertase gene. Doklady Biol. Sci. 434, 338-340. doi: 10.1134/S0012496610050133

Smeekens, S., Ma, J., Hanson, J., and Rolland, F. (2010). Sugar signals and molecular networks controlling plant growth. Curr.
Opin. Plant Biol. 13, 274-279. doi: 10.1016/j.pbi.2009.12.002

Snider, J. L., Oosterhuis, D. M., Loka, D. A., and Kawakami, E. M. (2011). High temperature limits in vivo pollen tube growth rates by altering diurnal carbohydrate balance in field-grown Gossypium hirsutum pistils. J. Plant Physiol. 168, 1168-1175. doi: 10.1016/j.jplph.2010.12.011

Solomon, B. D. (2010). Biofuels and sustainability. Ann. N.Y. Acad. Sci. 1185, 119-134. doi: 10.1111/j.17496632.2009.05279.x

Sturm, A. (1999). Invertases: primary structures, functions and roles in plant development and sucrose partitioning. Plant Physiol. 121, 1-7. doi: 10.1104/pp.121.1.1

Sturm, A., and Tang, G. Q. (1999). The sucrose-cleaving enzymes of plants are crucial for development, growth and carbon partitioning. Trends Plant Sci. 4, 401-407. doi 10.1016/S1360-138501470-3

Sunkar, R., Kapoor, A., and Zhu, J. K. (2006). Posttranscriptional induction of two $\mathrm{Cu} / \mathrm{Zn}$ superoxide dismutase genes in Arabidopsis is mediated by downregulation of miR398 and important for oxidative stress tolerance. Plant Cell 18, 2051-2065. doi: $10.1105 /$ tpc. 106.041673

Suwa, R., Hakata, H., Hara, H., ElShemy, H. A., Adu-Gyamfi, J. J., Nguyen, N. T., et al. (2010). High temperature effects on photosynthate partitioning and sugar metabolism during ear expansion in maize (Zea mays L.) genotypes. Plant Physiol. Biochem. 48, 124-130. doi: 10.1016/j.plaphy.2009.12.010

Thakur, P., Kumar, S., Malik, J. A., Berger, J. D., and Nayyar, H. (2010). Cold stress effects on reproductive development in grain crops: an overview. Environ. Exp. Bot. 67, 429-443. doi 10.1016/j.envexpbot.2009.09.004

Tognetti, J. A., Pontis, H. G., and Martínez-Noël, G. M. A. (2013). Sucrose signaling in plants: a world yet to be explored. Plant Signal. Behav. 8:e23316. doi: 10.4161/psb.23316

Umezawa, T., Yoshida, R., Maruyama, K., Yamaguchi-Shinozaki, K., and Shinozaki, K. (2004). SRK2C, a SNF1-related protein kinase 2, improves drought tolerance by controlling stress-response gene expression in Arabidopsis thaliana. Proc. Natl. Acad. Sci. U.S.A 101, 17306-17311. doi: 10.1073/pnas.0407758101

Vacca, R. A., de Pinto, M. C., Valenti, D., Passarella, S., Marra, E., and De Gara, L. (2004). Production of reactive oxygen species, alteration of cytosolic ascorbate peroxidase, and impairment of mitochondrial metabolism are early events in heat shock-induced programmed cell death in tobacco Bright-Yellow 2 cells. Plant Physiol. 134, 1100-1112. doi: 10.1104/pp.103.035956

Van Breusegem, F., Bailey-Serres, J., and Mittler, R. (2008). Unraveling the tapestry of networks involving reactive oxygen species in plants. Plant Physiol. 147, 978-984. doi: 10.1104/pp.108.122325

Van den Ende, W., and Valluru, R (2009). Sucrose, sucrosyl oligosaccharides, and oxidative stress: scavenging and salvaging. J. Exp. Bot. 60, 9-18. doi: 10.1093/jxb/ern297

Van Houtte, H., Vandesteene, L., López-Galvis, L., Lemmens, L., Kissel, E., Carpentier, S., et al. (2013). Overexpression of the trehalase gene AtTRE1 leads to increased drought stress tolerance in Arabidopsis and is involved in abscisic acid-induced stomatal closure. Plant Physiol. 161, 1158-1171. doi: 10.1104/pp.112.211391

Vilhar, B., Kladnik, A., Blejec, A., Chourey, P. S., and Dermastia, M. (2002). Cytometrical evidence that the loss of seed weight in the miniaturel seed mutant of maize is associated with reduced mitotic activity in the developing endosperm. Plant Physiol. 129, 23-30. doi: 10.1104/pp.001826

Volkov, R. A., Panchuk, I. I., Mullineaux, P. M., and Schöffl, F (2006). Heat stress-induced $\mathrm{H}_{2} \mathrm{O}_{2}$ is required for effective expression of heat shock genes in Arabidopsis. Plant Mol. Biol. 61, 733-746. doi 10.1007/s11103-006-0045-4

Wahl, V., Ponnu, J., Schlereth, A., Stéphanie, A., Langenecker, T., Franke, A., et al. (2013). Regulation of flowering by trehalose-6phosphate signaling in Arabidopsis thaliana. Science 339, 704-707. doi: 10.1126/science. 1230406

Wang, E., Wang, J., Zhu, X., Hao, W., Wang, L., Li, Q., et al. (2008). Control of rice grain-filling and yield by a gene with a potential signature of domestication. Nat. Genet. 40, 1370-1374. doi: 10.1038/ng.220

Wang, H., Schauer, N., Usadel, B., Frasse, P., Zouine, M., Hernould, M., et al. (2009). Regulatory features underlying pollination-dependent and -independent tomato fruit set revealed by transcript and primary metabolite profiling. Plant Cell 21, 1428-1452. doi: $10.1105 /$ tpc. 108.060830

Weber, H., Borisjuk, L., and Wobus, U. (1996). Controlling seed 
development and seed size in Vicia faba: a role for seed coat-associated invertases and carbohydrate state. Plant J. 10, 823-834.

Weber, H., Borisjuk, L., and Wobus, U. (2005). Molecular physiology of legume seed development. Annu. Rev. Plant Biol. 56, 253-279. doi: $\quad 10.1146 /$ annurev.arplant.56. 032604.144201

Weil, M., and Rausch, T. (1990). Cell wall invertase in tobacco crown gall cells: enzyme properties and regulation by auxin. Plant Physiol. 94, 1575-1581. doi: 10.1104/pp.94.4.1575

Weiss, Y. G., Bromberg, Z., Raj, N., Raphael, J., Goloubinoff, P., BenNeriah, Y., et al. (2007). Enhanced heat shock protein 70 expression alters proteasomal degradation of IkappaB kinase in experimental acute respiratory distress syndrome. Crit. Care Med. 35, 2128-2138. doi: 10.1097/01.CCM.0000278915. 78030.74

Weltmeier, F., Rahmani, F., Ehlert, A., Dietrich, K., Schutze, K., Wang, X., et al. (2009). Expression patterns within the Arabidopsis C/S1 bZIP transcription factor network: availability of heterodimerization partners controls gene expression during stress response and development. Plant Mol. Biol. 69, 107-119. doi: 10.1007/s11103-008-9410-9
Wind, J., Smeekens, S., and Hanson, J. (2010). Sucrose: metabolite and signaling molecule. Phytochemistry 71, 1610-1614. doi: 10.1016/ j.phytochem.2010.07.007

Xiang, L., Li, Y., Rolland, F., and Van den Ende, W. (2011). Neutral invertase, hexokinase and mitochondrial ROS homeostasis: emerging links between sugar metabolism, sugar signaling and ascorbate synthesis. Plant Signal. Behav. 6, 1567-1573. doi: 10.4161/psb.6.10. 17036

Xiong, Y., McCormack, M., Li, L., and Sheen, J. (2013). Glucose-TOR signalling reprograms the transcriptome and activates meristems. Nature 496, 181-186.

Xiong, Y., and Sheen, J. (2012) Rapamycin and glucose-target of rapamycin (TOR) protein signaling in plants. J. Biol. Chem. 287, 2836-2842. doi: 10.1074/jbc.M111.300749

Xu, S., Brill, E., Llewellyn, D., Furbank, R. T., and Ruan, Y. L. (2012). Over-expression of a potato sucrose synthase gene in cotton accelerates leaf expansion, reduces seed abortion and enhances fiber production. Mol. Plant 5, 430-441. doi: $10.1093 / \mathrm{mp} / \mathrm{ssr} 090$

Yanagisawa, S., Yoo, S. D., and Sheen, J. (2003). Differential regulation of EIN3 stability by glucose and ethylene signalling in plants. Nature 425, 521-525. doi: 10.1038/nature01984

Young, L. W., Wilen, R. W., and Bonham-Smith, P. C. (2004). High temperature stress of Brassica napus during flowering reduces microand megagametophyte fertility, induces fruit abortion, and disrupts seed production. J. Exp. Bot. 55, 485-495. doi: 10.1093/jxb/erh038

Zanor, M. I., Osorio, S., Nunes-Nesi, A., Carrari, F., Lohse, M., Usadel, B., et al. (2009). RNA interference of LIN5 in tomato confirms its role in controlling brix content, uncovers the influence of sugars on the levels of fruit hormones and demonstrates the importance of sucrose cleavage for normal fruit development and fertility. Plant Physiol. 150, 1204-1218. doi: 10.1104/pp.109.136598

Zhang, Y., Primavesi, L. F., Jhurreea, D., Andralojc, P. J., Mitchell, R. A. C., Powers, S. J., et al. (2009). Inhibition of Snf1- related protein kinase (SnRK1) activity and regulation of metabolic pathways by trehalose 6-phosphate. Plant Physiol. 149, 1860-1871. doi: 10.1104/pp.108.133934

Zinn, K. E., Tunc-Ozdemir, M., and Harper, J. F. (2010). Temperature stress and plant sexual reproduction: uncovering the weakest links. J. Exp. Bot. 61, 1959-1968. doi: 10.1093/jxb/erq053
Zinselmeier, C., Jeong, B. R., and Boyer, J. S. (1999). Starch and the control of kernel number in maize at low water potentials. Plant Physiol. 121, 25-35. doi: 10.1104/pp.121.1.25

Conflict of Interest Statement: The authors declare that the research was conducted in the absence of any commercial or financial relationships that could be construed as a potential conflict of interest.

Received: 09 April 2013; paper pending published: 02 May 2013; accepted: 10 July 2013; published online: 01 August 2013

Citation: Liu Y-H, Offler CE and Ruan $Y-L$ (2013) Regulation of fruit and seed response to heat and drought by sugars as nutrients and signals. Front. Plant Sci. 4:282. doi: 10.3389/fpls.2013.00282

This article was submitted to Frontiers in Plant Physiology, a specialty of Frontiers in Plant Science.

Copyright (c) 2013 Liu, Offler and Ruan. This is an open-access article distributed under the terms of the Creative Commons Attribution License (CC BY). The use, distribution or reproduction in other forums is permitted, provided the original author(s) or licensor are credited and that the original publication in this journal is cited, in accordance with accepted academic practice. No use, distribution or reproduction is permitted which does not comply with these terms. 